\title{
The International Multidimensional Fertility Index: The European Case
}

\author{
José María Fernández-Crehuet \\ Universidad a Distancia de Madrid \\ J. Ignacio Giménez-Nadal \\ University of Zaragoza, CTUR and BIFI \\ Ignacio Danvila Del Valle \\ Universidad Complutense de Madrid
}

\begin{abstract}
:
We propose an index to measure the degree of ability or desire of the population in a given country to have children, via an analysis of certain factors that may have a positive or negative influence on the fertility rate of that country. Using data for the twenty-eight countries of the European Union, and Principal Components Analysis, we construct the International Multidimensional Fertility Index (IMFI) as a combination of four dimensions: 1) Economy and family, 2) Attitudes and habits, 3) Work-Life Balance, and 4) Policy, along with nineteen distinct variables. We find that Denmark, the Netherlands, and Luxembourg are among the countries with the highest value of the index, and they also have high fertility rates within the EU. At the other end of the spectrum, Latvia, Cyprus, and Greece, are ranked in the last positions according to our index, countries that also present low values in their fertility rates. We also find a positive correlation between the value of our index and country fertility rates, an indication that our index may be capturing country differences in the conditions for bearing children, with higher values of the index indicating better conditions for childbirth and childrearing. To the extent that international data becomes available, our methodology will allow for the construction of international rankings, helpful in identifying cross-country differences in in the conditions for fertility.
\end{abstract}

Keywords: Europe, International Multidimensional Fertility Index, Fertility Rates, Principal Components Analysis

JEL: I31, J12, J13 


\section{Introduction}

The last half-century has seen a broad decline in fertility in the European Union, a decline directly related to social change resulting from evolving roles, by gender and within the family. Fertility has been a central topic of research in sociology, anthropology, economics, medicine, and psychology (Balbo et al., 2013) and, since the birth of modern civilization, it has been of primary public concern (Esping-Andersen, 2013). ${ }^{1}$ Since the 1970s, the majority of advanced societies have seen their fertility rates fall below replacement level. The result is a large number of countries experiencing a historically unique phenomenon, what demographers define as the "lowest-low fertility" consistent with a period of total fertility rate at or below 1.3 (Billari and Kohler, 2004; Kohler et al., 2002). But since the early 2000s, there have been some signs of fertility recovery in certain developed countries (Myrskylä et al., 2009) as the number of countries with lowest-low fertility rates diminished considerably, from 21 in 2003 to only 4 in 2008 (Goldstein et al., 2009), while a handful of advanced countries, such as the United States, Australia, Sweden, Norway, and France, have achieved fertility levels close to replacement. This reversal is mostly the result of the slowing-down of fertility postponement and the recuperation of postponed childbearing among older women (Bongaarts and Sobotka, 2012). The global economic downturn after 2008 led to stagnant or declining fertility in many countries, and by 2011, several Eastern European countries (such as Hungary, Poland, and Romania) had returned to a lowest-low fertility scenario, with all the Southern European countries following close behind.

In recent years, increased attention has been paid to the possibility that immigrants could help lessen the negative consequences of low fertility, given the higher fertility rates of immigrants (Lutz and Scherbov, 2002). Several studies have shown, however, that the aggregate impact of migrants on overall fertility levels, although not trivial, is rather modest (Roig and Castro-Martín, 2007). For instance, in the case of Spain, one of the main migrant-receiving countries of Europe before the onset of the economic crisis, the annual number of births rose dramatically, from 365,193 in 1998 to 519,779 in 2008. But Castro-Martín and Rosero-Bixby (2011) estimate that immigrant contributions to Spain's fertility rate have been relatively small. This surprisingly small contribution is a result of their relatively low share of the childbearing population and also of the sustained decline in the fertility rates of foreign women.

\footnotetext{
${ }^{1}$ If we understand fertility as the production of a live birth (natality), several measures can be used to measure fertility in a country: the "child-woman ratio", defined as the number of children under age 5 per 1,000 women of childbearing age in a given year, the "crude birth rate", defined as the number of live births per 1,000 population in a given year, the "general fertility rate", defined as the number of live births per 1,000 women aged 15-49 in a given year, and the "total fertility rate", defined as the number of children that would be born to a woman if she were to live to the end of her childbearing years and bear children in accordance with current age-specific fertility rates. Any fertility measure has its advantages and disadvantages. For instance, crude fertility rates are not good for crosspopulation comparisons, as variations in the age distribution of the populations compared will affect the birth rate. For a complete view of the fertility behavior of women in a country, we refer to "total fertility rate" throughout the paper.
} 
One reason to analyze the fertility behavior of individuals in a country is the negative consequences of low fertility. Below-replacement fertility presents certain economic challenges for a society, since it changes the age structure of the population and may require structural adaptations, with important implications for welfare (Weil 1999) and pay-as-you-go pension systems (Rindfuss et al. 2003). Thus, the well-being of society depends to a large extent on its capacity to maintain a level of fertility that will guarantee both generational replacement and sufficient economic growth to sustain a welfare state that can respond to the challenges of an increasingly ageing population with increasing levels of dependency. In fact, population ageing is a pressing public issue. Another reason evolves from a welfare perspective, as in the Nordic countries (where family benefits are comparatively generous), the role of fertility is defined as a public recognition that children are a positive societal good, and the associated costs must therefore be shared by all. Thus, analyzing the factors that contribute to higher levels of fertility may be helpful for policy makers, in that it may help Governments to devise and implement policies aimed at increasing fertility rates of the countries.

We offer a global view of the phenomena, ranking European countries according to the ability or desire of their populations have to have children, based on a range of factors defined at the country level. We use data from twenty-eight European countries, and the Principal Components Analysis technique, to construct the International Multidimensional Fertility Index (IMFI) as a combination of four dimensions, with nineteen variables: 1) Economy and family, 2) Attitudes and habits, 3) Work-life balance, and 4) Policy. We find that Denmark, the Netherlands, and Luxembourg are among the countries with the highest values of the index, and they also have high fertility rates within the EU. At the other end of the spectrum, Latvia, Cyprus, and Greece, are ranked in the last positions on our index, and they also present low values of fertility rates. Not surprisingly, we find a positive correlation between the value of our index and country fertility rates, indicating that we may be capturing country differences in the conditions for bearing children, with higher values of the index indicating better conditions for childbirth and childrearing.

We contribute to the literature by proposing an index that ranks the ability or desire of the population in a given country to have children. In the process, we pool several factors, clustering them according to different dimensions, and constructing a ranking based on these factors. Furthermore, our analysis recognises the multidimensional nature of the fertility phenomena. We are not aware of any comparable index that considers so many factors as contributors to fertility, although the OECD, with the program "Doing Better for families", has compiled a database of cross-international indicators of the situation of families and children, Thévenon (2011) employs principal component analysis to identify clusters of countries with broadly comparable family policy packages, and Pascall and Lewis (2004) identify five 
components (paid work, care, income, time, and voice) within which gender-equity policies must be constructed. Our proposal includes four dimensions with nineteen variables, where other social aspects, such as attitudes and the possibility of changing or adapting work schedules, are taken into account in the computation. As international data becomes available, the conclusions drawn in this paper may provide a promising line of research, since our methodology will allow for the construction of international rankings, and will be helpful in identifying cross-country differences in conditions for fertility.

The remainder of the paper is organized as follows. Section 2 describes the background used for the inclusion of the four dimensions of IMFI. Section 3 presents the main variables, measured at the international level, used to compute the index. Section 4 presents the methodology, and Section 5 describes the computation of the IMFI, and the main results of our cross-country comparisons. Section 6 presents our main conclusions.

\section{Background}

There is a quite significant variation in fertility levels across advanced societies. In 2010, the total fertility rate ranged from 1.17 (Latvia) to 2.2 (Iceland) in Europe, and from 1.23 (Korea) to 3.03 (Israel) among OECD countries. In the specific case of European countries, most European countries have fertility rates below 2.1, but there are variations. Southern (Spain, Italy, Greece, Portugal), Eastern (Poland, Hungary, Slovakia) and Central Europe (Germany) currently display the lowest fertility rates, while Northern and Western European countries (Sweden, France, the United Kingdom, Ireland, and Iceland) lie very close to replacement level. Furthermore, there appear to be two pathways to moderately high fertility: the Nordic model, based on public support for the dual-earner family, and family-friendly policies aimed at facilitating the reconciliation of the employment and care responsibilities of both mothers and fathers, and the Anglo model, based on the persistence of high-fertility niches (Castro-Martín and MartínGarcía, 2014). Thus, there are large cross-country variations in fertility rates. We propose the IMFI as a specific tool for documenting and analyzing the degree of ability or desire of the population in a given country to have children, examining certain crucial factors that can have a positive or negative influence on the fertility rate of a given country.

For the construction of the index, we identify several factors that may be related to the fertility behaviour, based on the existing literature. Then, we group these factors in four categories, according to their pertinence to the following aspects: Economy and family, Attitudes and habits, Work-life balance, and Policy. The Economy and family category captures macroeconomic conditions and family patterns, the Attitudes and habits category captures subjective factors, such as preferences or attitudes, that may be conditioning the fertility 
behaviour of individuals, the Work-life balance category captures factors associated with the quantity and quality of work, and the Policy dimension captures factors associated with Government policies.

For the Economy and family, we consider factors related to the population of childbearing age, regarding living conditions in their families. The first refers to the economic possibilities, measured by household income and labor market participation. It is widely accepted that a minimum level of stability is a prerequisite for setting up an independent household and having children (González and Jurado-Guerrero, 2006), and thus unemployment may affect stability by reducing household income. Thus, we consider unemployment as a negative factor affecting fertility behaviour (Örsal and Goldstein, 2010), and several studies have shown that income and job insecurity largely discourage family formation (De la Rica and Iza, 2005; Vignoli et al., 2012). In the current context, certain countries are experiencing high levels of unemployment; in Spain, for example, where unemployment reached a record high of $26 \%$ (in Greece 27\%) at the end of 2013 - and 46\% among those under age 25 - there is little indication that these rates will recede any time soon. In this context, a significant recovery of fertility is difficult to imagine (Castro-Martín and Martín-García, 2014). Of special relevance are the unemployment rates of the young, as they are the ones who are most likely (in 'normal' times) to be having children, and thus we include unemployment rates for the young in those countries.

Another economic factor that may affect fertility behavior is that of gender equality in the labor market, which is necessary to encourage an increase in fertility (McDonald, 2002). Myrskylä et al. (2011) show that gender equality is a necessary condition for a reversal of the relationship between fertility and higher levels of socio-economic development. This is also consistent with the idea that societies may reach a comparatively higher fertility equilibrium once they manage to effectively reconcile motherhood with female labour-force participation, consistent with the work of Esping-Andersen and Billari (2012) on the link between high fertility and compatibility with gender-egalitarian arrangements (Miller Torr and Short 2004). Esping-Andersen and Billari (2012) propose that a recovery of fertility is expected when gender equality becomes dominant, triggered by the rise in women's education. In order to measure gender equality in the labor market, we use the wage gender gap in the country, a measure traditionally linked to the fertility behavior of women (Galor and Weil, 1996; Momota, 2000).

Economic conditions may also shape family life and partnership dynamics, which have undergone profound changes in all Western societies in recent decades (Bumpass, 1990; Billari, 2005). Some of the key transformations have been later entry into conjugal unions, the declining significance of marriage, the spread of cohabitation and living-apart-together relationships, the increase in separation and divorce, and the increase in re-partnering and step-families (Seltzer, 2000; Kiernan, 2001). Additionally, there exist cross-country differences in family life and 
partnership dynamics, especially for the young. Prior research has found large cross-country differences in the age at which residential independency is established (Becker et al., 2010; Angelini et al., 2011; Angelini and Laferrère, 2013), and cross-country differences in the nestleaving behaviour of the young, and marriage formation, may help explain cross-country differences in fertility behaviour. Thus, as factors affecting fertility behaviour, we consider the nest-leaving behaviour of the young, along with rates of union formation.

Attitudes and habits are related to fertility, and have the commonality that represents subjective judgements or preferences. One factor with a clear relationship to fertility behaviour is intended fertility. Recent data on fertility intentions, collected in the Eurobarometer in 2011, confirm that the two-child norm is strongly entrenched in all European countries (Testa, 2012). Ideal family size refers to the number of children a person would like to have, irrespective of whether it is possible, and it is therefore likely to be influenced by prevailing social norms. In all the countries examined, women's and men's ideal number of children is above 2 and reaches nearly 2.5 among women in France and Sweden. Thus, an important determinant of fertility is related to how many children individuals think are desirable, and we will take this into account in our analysis. Other attitudes or preferences do not directly bear on the ideal number of children, but rather to the interaction between children, the labor market, and the family. To the extent that work and household responsibilities interact, attitudes of individuals towards the family, work, and children may be important in determining fertility behaviour. Thus, we also include questions about attitudes towards family, children, and work. We also consider the attitude towards the global population and its interaction with resources, as more individual concerns about population and resource scarcity may imply a preference for adoption rather than having children, even though the adoption process carries with it quite stringent legal requirements and may limit the number of children individuals can adopt.

The Work-life balance category allows us to incorporate those aspects of daily life, balancing work and household responsibilities, that may lead to fertility postponement or a decline in fertility. The relationship between employment and fertility does not depend only on hours worked, but is largely conditioned by institutional arrangements, welfare policies, gender relations, the functioning of the labour market, and the social organization of work. A number of studies suggest that it is not merely employment versus non-employment, contract duration, or the number of hours worked that matter for childbearing; work schedules and time flexibility, job characteristics such as autonomy, and workplace organization are increasingly considered important in terms of reconciling family and work (Begall and Mills, 2011; Drobnič and Guillén-Rodríguez, 2011). Societies with high levels of female employment have introduced measures that help reconcile motherhood with careers (Bernhard, 1993; Brewster and Rindfuss 2000), and the evidence points toward the existence of two dimensions regarding the work-life 
balance: the quantity of work, and the quality of work. . Thus, in this category, we consider the number of hours of work, on the one hand, and measures aimed at capturing the flexibility of work, on the other hand.

Finally, in Policy, we consider what government or regulatory actions can help households in their childrearing activities. This is an important dimension, as an extensive literature has studied the effect of family policies on fertility (see Gauthier, 2007 for a review). Welfare states vary considerably in terms of the introduction of such features as parental leave, public childcare, and family allowances. Comparative macro-level analyses based on aggregate data suggest a positive correlation between total fertility rates and public spending on family policies and childcare availability (Bradshaw and Finch 2003; Bonoli 2008). Some policies (e.g., parental leave, formal childcare) can promote gender equality by reducing the opportunity costs of children; others, such as child benefits, may only help to reduce the direct costs of children (Baizán et al., 2014). Changes or differences in maternal leave conditions have also been shown to affect fertility (Gauthier and Hatzius, 1997). Governments can implement policies to help households to have the number of children they desire, at the time of their choosing (Thévenon and Luci 2012), and we consider the spending by national Governments on family policies, and the availability of public childcare services, as indicators. Additionally, maternal leave conditions differ across countries, and we also take this into account in compiling our index.

\section{Data}

We focus on the following countries: Austria, Belgium, Bulgaria, Croatia, Cyprus, Czech Republic, Denmark, Estonia, Finland, France, Germany, Greece, Hungary, Ireland, Italy, Latvia, Lithuania, Luxembourg, Malta, the Netherlands, Poland, Portugal, Romania, Slovakia, Slovenia, Spain, Sweden and the United Kingdom. Thus, our analysis considers 28 European Union countries, and for each variable included in the analysis we have 28 values, one per country. Here we must acknowledge that information on the variables does not always refer to the same years, and while most the data refers to the year 2012, in some cases the data refers to 2008 and 2011. For example, while for the categories of Economy and family, Work-life balance, and Policy, the data used for the analysis is for the year 2012, for the data regarding Attitudes and habits the data is for previous years. This combination of data sources from different years could generate a problem in terms of interpretation or applicability of results. However, we can assume that attitudes and habits in societies are quite stable over time (Eagly and Chaiken, 1993; Tesser, 1993; Olson et al., 2001), and so any differences between the years 2008 and 2012 will be minimal, which would not affect our results. 
For our empirical analysis, we use the following datasets: 1) the European Values Study (EVS) in 2008; 2) the European Working Conditions Survey (EWCS) 2010, 3) the European Quality of Life Survey (EQLS) 2012, 4) EUROSTAT Statistics, and 5) the OECD Family Database. The EVS is a large-scale, cross-national, and longitudinal survey research program on how Europeans think about family, work, religion, politics and society. Repeated every nine years in an increasing number of countries, the survey provides insights into the ideas, beliefs, preferences, attitudes, values, and opinions of citizens all over Europe. The research program was initiated by the European Value System Study Group (EVSSG) in the late 1970s and has emerged as a well-established network of social and political scientists aiming at high standards in data creation and processing. From 1981 to 2008 four waves of survey were conducted in European and other countries, and we choose the 2008 wave for the analysis.

The EWCS has been developed by EUROFOUND, and has become an established source of information about working conditions and the quality of work and employment. With five waves implemented since 1990, it enables monitoring of long-term trends in working conditions in Europe. The themes covered include employment status, working time arrangements, work organization, learning and training, physical and psychosocial risk factors, health and safety, worker participation, work-life balance, and earnings and financial security, as well as work and health. The EQLS, implemented in 2003, 2007, and 2011-12, provides a comprehensive portrait of living conditions in European countries. It contains a broad range of indicators on various dimensions of quality of life, both objective and subjective. In addition, some EQLS questions were used in a Special Eurobarometer on Poverty and Social Exclusion, in autumn 2009 and 2010. Given the recent high level of interest in the quality of life of European citizens, the EQLS is increasingly important in its contribution to the political and academic debate.

EUROSTAT is the statistical office of the European Union, in Luxembourg. Its task is to provide the European Union with statistics at EU level that enable comparisons between countries and regions. EUROSTAT offers a whole range of important and interesting data that governments, businesses, the education sector, journalists, and the public can use for their work . Finally, the OECD Family Database was developed to provide cross-national indicators on family outcomes and family policies across the OECD countries, its enhanced engagement partners, and EU member states. The database brings together information from various national and international databases, both within the OECD (see related OECD databases) and external organisations. The database currently includes 70 indicators under four main dimensions: (i) structure of families, (ii) labour market position of families, (iii) public policies for families and children, and (iv) child outcomes. Each indicator typically presents the data on a particular issue as well as relevant definitions and methodology, comparability and data issues, information on 
sources and, where relevant, includes the raw data or descriptive information across countries.

(Direct links to the different databases can be found at the end of this paper.)

\section{Economy and family}

We include factors related to the wage gender gap, unemployment, and the family situation of young people. The Average gender wage gap is measured as the difference between male and female average gross hourly earnings, as a percentage of average gross hourly earnings of male paid employees (EUROSTAT, 2012). ${ }^{2}$ The Total unemployment rate is measured as unemployed persons as a percentage of the active population (EUROSTAT, 2012). The Youth unemployment rate is measured as unemployed persons aged 15-29 as a percentage of the active population in the same age group (EUROSTAT, 2012). The \% young people living with parents is measured as unemployed youths as a percentage of the active population. The Crude marriage rate is defined as the ratio of the number of marriages during the year to the average population in that year (the value is expressed per 1,000 inhabitants) (EUROSTAT, 2012).

\section{Attitudes and habits}

We include factors related to ideal fertility, and family- and work-related attitudes and values. The Ideal number of children for females is obtained from OECD statistics, measuring the average response to the question "Generally speaking, what do you think is the ideal number of children for a family?" The main indicator underlying the key findings here is the mean personal ideal number of children, reflecting the number of children that individuals consider as ideal for themselves, averaged across respondents. Values are for the year 2011 (OECD Family Database). The interpretation of this variable is clear, as higher values reflect a greater preference for more children, which would contribute to higher fertility rates in the country. ${ }^{3}$

The statement, Family is important in life is measured as the percentage of people answering "very important" or "quite important" to the question "how important is family in your life" (European Values Study, 2008). The Importance of children for marriage is measured as the percentage of people answering "very important" or "rather important" when asked about children in the statement "Here is a list of things which some people think make for a successful

\footnotetext{
${ }^{2}$ When we refer to EUROSTAT for the year 2012, we have considered the average values of the years 2010, 2011 and 2012 when the information is available for the indicator.

${ }^{3}$ The use of fertility intentions data has been criticized, as respondents tend to give socially desirable answers, many individuals revise their fertility goals over the course of their lives, and there is a high level of uncertainty attached to reproductive plans (Ní Bhrolcháin and Beaujouan, 2012). Despite these shortcomings, childbearing preferences play a central role in fertility decision-making and are typically considered to be influential predictors of future childbearing behavior (Philipov, 2009).
} 
marriage. Please tell me, for each one, whether you think it is very important, rather important or not very important for a successful marriage?" (European Values Study, 2008). All these questions are measured as dummy variables taking value " 1 " if the individuals consider the statement is "very important" or "rather important", and takes value " 0 " if the individuals consider the statement "not important". Women prefer home and children is measured as the percentage of people answering "agree strongly" or "agree" to the statement "A job is alright but what most women really want is a home and children (European Values Study, 2008). Work always comes first is measured as the percentage of people answering "agree strongly" or "agree" to the statement "Work should always come first, even if it means less spare time" (European Values Study, 2008). Reaching the limit of population is measured as the percentage of people answering "agree strongly" or "agree" to the statement "We are approaching the limit of the number of people the earth can support" (European Values Study, 2008). All these questions are measured as dummy variables taking value " 1 " if the individuals "agree strongly" or "agree" to the different statements, and take value " 0 " if individuals "disagree" or "strongly disagree".

\section{Work-life balance}

We include factors related to the intersection between work and family life, including the quantity and quality of work, in terms of reconciliation between the work and family sectors. Weekly hours in work are measured as the average number of normal, weekly hours of work in main job (EUROSTAT, 2012). The Level of stress due to work-life balance is measured as the percentage of individuals responding "At work and at home" to the question "Do you have stress due to work-life balance issues" (EUROFOUND, 2010). Flexibility to change work schedule is measured as the percentage of people who replied "yes" to the question "I can vary my start and finish times" (EUROFOUND, 2010). Flexibility to accumulate hours of work is measured as the percentage of people who replied "yes" to the question "I can accumulate hours for time off' (EUROFOUND, 2010). Flexibility to take a day off is measured as the percentage of people who replied "yes" to the question "I can take a day off in the short run if I need it" (EUROFOUND, 2010).

\section{Policy}

We consider factors related to governmental policies focused on helping households in their childrearing activities. The \% of GDP spent on family benefits is measured as the percentage of GDP spent in schemes for family and children (EUROSTAT, 2012). The $\%$ of children $<3$ in formal education is measured as the percentage of children under age 3 in formal childcare, over 
the total population of children under 3 (EUROSTAT, 2012). The Duration of maternity leave is measured as the number of weeks of maternity leave, according to employment-protected statutory maternity leave (OECD).

\section{Methodology: The Principal Components Analysis (PCA) Approach}

In the construction of our index, we use Principal Components Analysis (PCA) for the selection of the variables and the choice of variable weights. PCA assumes full compensability among variables, in the sense that any deficit in one dimension can be compensated for with a suitable surplus in another. But, as argued by Tarabusi and Guarini (2013), complete compensability among the main dimensions of the index is often not desirable. Alternative calculations using non-linear functions, which allow for penalizations, could be proposed. However, given the common practice of using PCA in the literature (Lai, 2003; Khrisnakumar and Nagar, 2008; Bellidoet al., 2011; Fernandez-Crehuet et al., 2016), we use the PCA as a weighting method.

The use of PCA to construct composite indexes has been proposed as a statistical method to build composite indicators, and dates back to Hotelling (1933). ${ }^{4}$ One of the earliest studies using PCA is Ram (1982), who applied the technique to form a composite index. Bellido et al. (2011) used PCA to elaborate a composite index of general satisfaction for the unemployed, FernandezCrehuet et al. (2016) used PCA to build a composite index to measure cross-country differences in work-life balance practices (the International Work-Life Balance index), and Filmer and Pritchett (2001) reviewed several standard options for evaluating different assets, and demonstrated the validity and usefulness of using PCA to generate a wealth index. Other studies using PCA to build composite (multidimensional) indices are Lai (2003) and Krishnakumar and Nagar (2008). However, it must be noted that PCA loadings are highly 'elitist', preferring highly-correlated variables to poorly-correlated variables, irrespective of the (possible) contextual importance of the latter set of variables (Mishra, 2007).

We use the methodology described in the OECD handbook (OECD, 2008), which includes the application of PCA analysis, for the construction of the Technology Achievement Index (TAI), applied to 28 countries. PCA groups together individual indicators that are collinear to form a composite indicator that captures as much as possible of the information common to individual indicators. The idea of PCA is to account for the greatest possible variation in the indicator set, using the smallest possible number of factors, and weighting intervenes only to

\footnotetext{
${ }^{4}$ PCA analysis is usually used in a framework of reflective formative models, where causality is determined from the concept to the variables chosen to measure the concept (see Diamantopoulos et al. (2008) for a review). However, in the current context, a "formative" model should be used, as we aim to measure the concept (e.g., fertility rates) with several variables. Thus, we cannot talk about causality, but only about correlations or associations between the fertility rates of the countries, and the index and components created using the PCA technique.
} 
correct for overlapping information between two or more correlated indicators (and is not a measure of the theoretical importance of the associated indicator).

One of the requirements for a correct application of PCA is that variables must be measured on the same scale. While there is, on occasion, no need to normalize the variables, as they are already measured on the same scale (Nardo et al., 2004), in other cases, variables must be normalized. Table 1 shows the values of each variable for each country, and it can be seen that our original variables are measured on different scales (e.g., percentage points, thousands...), and thus we need a way to normalize them. Several methods have been proposed in the literature, including rank of observations, standardization (or z-scores), min-max, distance to or from a reference, or indicators above or below the mean (OECD, 2008). Each normalization method has its advantages and disadvantages regarding the loss of interval-level information, sensitivity to outliers, arbitrary choice of categorical scores, and sensitivity to weighting. In order to allow for positive values of all the variables, the Gaussian and the distances to the mean or the median must be excluded, as they could lead to negative values of certain variables. The normalization method we select is standardization, which is the use of z-scores of the variables. In doing so, we calculate the average () and standard deviation (ㅁ) of the variables, and the $\mathrm{z}$ score is calculated as $z=\frac{x-\mu}{\sigma}$, where " $\mathrm{x}$ " represents the value of the variable for the different countries.

Next, we must choose which variables to include in the index, as part of any of the 4 dimensions, and several criteria are used in this step. ${ }^{5}$ A first criterion consists of analyzing the relationship among the variables included in each of the four dimensions. We must analyze the correlation structure of the variables to be included in each domain, since if the variables are too strongly correlated, the weights may be misleading and the results are unstable (PCA is very sensitive to collinearity). A second criterion for the selection of variables to be included in the index refers to factor loadings. We only choose those variables whose factor loadings have a minimum value, given that variables with low factor loadings have only a small role in explaining the variance of the domain. We select only those variables whose factor loadings (obtained using the varimax rotation) are higher in absolute value than 0.40 . Variables whose factor loadings are lower than 0.40 in absolute value are excluded from the analysis.

Once the variables to be included in each dimension are selected, using the above criteria, a specific weight must be assigned to each variable that will determine the importance of the

\footnotetext{
${ }^{5}$ Originally, the IMFI was composed of 27 variables, distributed in 4 dimensions. After the application of the criteria for the selection of variables, and confirmatory factor analysis, we have dropped 8 variables from the index: "Crude divorce rates", "Ideal number of children for males", "Importance for job to be family-friendly", "Women need children to be fulfilled", "Average holidays", "\% of people working at home", "Commuting time per working day", and "Average payment on maternity leave". More information about data sources for these variables can be obtained on request.
} 
variable in the corresponding dimension. To assign weights, several methods have been proposed, including arithmetic weighting, geometric weighting, the use of expert opinion (via surveys or the Delphi method), and the use of factorial analysis. We employ PCA in generating the IMFI, and follow the methodology described in OECD (2008) to build the TAI index. The approach is similar to the approach used by Nicoletti et al., (2000), who group the individual indicators with the highest factor loadings into intermediate composite indicators. Several steps must be taken in order to build the index.

For the assignation of weights to the variables, we first select the number of components for each dimension. There are several criteria that can be followed in selecting the number of components in the reference dimension, and according to OECD (2008), we jointly apply the following criteria: (i) have associated eigenvalues greter than one; (ii) contribute individually to the explanation of overall variance by more than $10 \%$; and (iii) contribute cumulatively to the explanation of the overall variance by more than $60 \%$.

Second, we use factor loadings to assign variables to each component. The idea is to use the factor loadings given by the PCA (using the varimax rotation) to assign the variables to the components, where each variable is assigned to the component where the factor loading is the highest in absolute value. For instance, if we consider the variable Average gender gap, the factor loadings for this variable are $-0.097,0.780$ and -0.149 in the first, second and third components, respectively. Given that the highest factor loading corresponds to the second component, we assign this variable to the second component of the dimension.

Third, we construct the weights using the matrix of factor loadings, after varimax rotation. Following OECD (2008) in its computation of the TAI index, all the original factor loadings obtained from the PCA are transformed to their squares, given that the square of factor loadings represents the proportion of the total unit variance of the indicator that is explained by the factor. Then, we sum all the squared factors of each component and divide the squared factor loadings by that same sum. For instance, for the variable average gender gap of component 2 of the Economy and Family dimension, the original factor loading of the variable is 0.56 , and its square is 0.3136 . We correct this squared factor loading by dividing by the sum of all the squared factor loadings of the variables in component 2 (i.e., 1.006), which leads to the value of 0.31 .

Finally, we build the final weight of the variables to be included in each dimension, using the squared factor loadings scaled to sum unity, and corrected using the proportion of total variation that each component is able to explain. For example, if we consider the Economy and Family dimension, components 1,2 and 3 of this dimension are able to explain $43 \%, 25 \%$, and $20 \%$ of the total variation, and thus explain $88 \%$ of the total variation. Out of this total explained 
variation, components 1,2 and 3 represent $49 \%(43 * 100 / 88), 29 \%(25 * 100 / 88)$, and $22 \%$ $(0.20 * 100 / 88)$ of the explained variation. We use these percentages of the relative explained variation to correct the squared factor loadings of the variables, obtaining the final weights.

\section{The International Multidimensional Fertility Index}

First, we analyze the correlation structure of the variables to be included in each domain, since if the variables are too strongly correlated, the weights may be misleading and results are unstable. Tables $2 \mathrm{~A}$ to $2 \mathrm{D}$ show the correlational structure of the variables included in each of the four domains, and we observe that there are high correlations between the variables of youth unemployment rates and total unemployment rates (0.95) for the Economy dimension, between importance of marriage for children and women prefer home and children (0.84) of the Attitudes and habits dimension, between weekly hours of work and level of stress due to worklife balance (0.74) of the Work-Life Balance dimension, between weekly hours of work and flexibility to change work schedule (-0.74) of the Work-Life Balance dimension, and flexibility to change work schedule and level of stress due to work-life balance (-0.77) of the Work-Life Balance dimension. Despite that the level of correlation between pairs of variables is high, we still include them in the index, since the factor loadings are larger than the lower limit we impose in the next step.

Tables A1, A3, A5 and A7 of the appendix show the results of applying PCA to the variables included in the dimensions of Economy and family, Attitudes and habits, Work-life balance and Policy, respectively. For the Economy and family dimension, we choose the first 3 components, as their eigenvalues are close to or more than unity $(2.17,1.26$, and 0.98 for the first, second and third components, respectively), the variation explained for each component is greater than $10 \%$ (43\%, 25\%, and $20 \%$ for the first, second and third components, respectively), and jointly they are able to explain $88 \%$ of the variation. For the Attitudes and Habits dimension, we choose the first 4 components, as their eigenvalues are close to or more than unity $(2.45,1.11,0.99$ and 0.94 for the first, second, third and fourth components, respectively), the variation explained for each component is greater than $10 \%(41 \%, 19 \%, 16 \%$, and $16 \%$ for the first, second, third and fourth components, respectively), and jointly they are able to explain $92 \%$ of the variation. For the Work-Life Balance dimension, we choose the first 3 components, as their eigenvalues are close to or more than unity in the two first components (3.84 and 0.82 for the first and second components, respectively), the variation explained for each component is greater than $10 \%$ $(62 \%, 17 \%$, and $12 \%$ for the first, second and third components, respectively), and jointly they are able to explain $90 \%$ of the variation. Finally, for the Policy dimension, we choose the first 3 components, as the variation explained for each component is greater than $10 \%$ (54\%, 31\%, and 
$15 \%$ for the first, second and third components, respectively), and jointly they are able to explain $100 \%$ of the variation.

Factor loadings are shown in Panels A of Tables A2, A4, A6 and A8 of the appendix for the dimensions Economy and family, Attitudes and habits, Work-life balance and Policy, respectively (in bold the highest factor loadings of the variables, which correspond to the component where the variables are assigned). Following our assignment rule, we assign the variables as follows: for the Economy and family dimension, the variables total unemployment rates, youth unemployment rates and \% of people living with parents are assigned to component 1 , average gender gap is assigned to component 2 , and crude marriage rates is assigned to component 3; for the Attitudes and habits dimension, the variables Importance of children for marriage, Women prefer home and children and Work always comes first are assigned to the first component, Reaching the limit of population is assigned to component 2, Ideal number of children for females is assigned to component 1, and Family is important in life is assigned to component 4; for the Work-Life Balance dimension, the variables Weekly hours of work, Level of stress due to work-life balance and Flexibility to change work schedule are assigned to component 1, Flexibility to take a day off is assigned to component 2, and Flexibility to accumulate hours of work is assigned to component 3; for the Policy dimension, the variable \% of GDP spent on family benefits is assigned to component 1, Duration of maternity leave is assigned to component 2 , and \% of children $<3$ in formal education is assigned to component 3.

Considering the Economy and family dimension, the final weights for the variables total unemployment rates, youth unemployment rates and \% of people living with parents are equal to $0.196\left(0.398^{*} 0.492\right), 0.204(0.415 * 0.492)$ and $0.081(0.164 * 0.492)$ given that they are assigned to component 1 , the final weight for the variable average gender gap is equal to 0.174 $(0.609 * 0.252)$ as it is assigned to component 2 , and the final weight for the variable crude marriage rates is equal to $0.215(0.983 * 0.223)$ given that it is assigned to component 3 . Following this method, we have computed the weights for the rest of variables, and results are shown in Table 3. Here we must emphasise that if the original factor loading is negative, weights are computed with a negative sign.

Following this step, we are able to construct 4 intermediate indices (i.e., dimensions), and if we analyze the correlations of the dimensions with the fertility rates of the countries, we obtain that, while the correlations between fertility rates and the Economy and family and Attitudes and Habits dimensions are negative (-0.331 and -0.417 , respectively), the correlation between 
fertility rates and the Work-Life balance and Policy dimensions are positive $(0.720$ and 0.555 , respectively). ${ }^{6}$

The Economy and family, Attitudes and habits, Work-life balance and Policy dimensions are comprised of 5, 6, 5, and 3 items, respectively. Here, following Spector (1992), we establish the minimum number of items per dimension as 3 , noting that three items per dimension should be viewed as an absolute minimum, and certainly not as an optimal number. In practice, it is not unusual to see individual dimensions that include 10, 20, or even more items to assess a single construct. Other things held constant, the more items in the dimension, the more reliable it is, and thus the Policy dimension could be considered as being less reliable than the rest of the dimensions. We apply confirmatory factor analysis to the 4 intermediate indices to check the consistency of the models. In doing so, we follow Kolenikov (2009) and use the LR goodnessof-fit test to see how the models fit the data. Using this measure, researchers can only convincingly claim that their models are compatible with the data if the model fit is satisfactory, and the null hypothesis is not rejected. The LR test has asymptotic $\chi^{2}$ distribution, with degrees of freedom equal to the number of over-identifying model conditions. In doing this, we use the Satorra-Bentler (Satorra and Bentler, 1994) "robust" standard errors to estimate the variancecovariance matrix. When we consider the dimensions of Economy and Family, Attitudes and habits and Work-life balance, the LR goodness of fit test presents values of 7.436, 13.113 and 0.437 , which, compared with the $\chi^{2}$ of 5,9 , and 5 degrees of freedom, indicates that the $\mathrm{p}$ values of the test are $0.190,0.158$, and 0.994 . These values indicate that we cannot reject the null hypothesis, and thus we can assume that the 3 models are compatible with the data. For the dimension of Policy, there are not sufficient degrees of freedom to perform the LR goodness-offit test, but we apply the LR test of independence, where we compare the current model with a model whose variables are assumed to be independent. The LR test of independence yields a value of 10.998, which, compared with the value of an $\chi^{2}$ of 3 degrees of freedom, indicates that we reject the null hypothesis of independence of variables. Thus, the Policy dimension remains a significant improvement.

Table 4 shows the results of the computation of the IMFI for selected countries, sorted from the highest to the lowest value of the index. For its computation, we use equal weights of the dimension, considering whether the intermediate dimensions yield a positive or negative correlation with fertility rates of the countries. For each country, we sum the values of the Work-

\footnotetext{
${ }^{6}$ We have also run an OLS regression of fertility rates on the four dimensions of the index. We observe that dimensions 1 and 2 have coefficients that are not statistically significant, while coefficients of dimension 3 and 4 are statistically significant at the $95 \%$ level. Thus, it seems that the Work-life balance and Policy dimensions have a higher explanatory power for fertility rates, in comparison with the Economy and family and Attitudes/habits dimensions. However, the current analysis does not allow us to establish a causal link between fertility rates and the dimensions, as the definition of the dimensions will change over time, as will the relationship across the variables.
} 
life balance and Policy dimensions, and the rest of the values of the Economy and family and Attitudes and habits dimension. Among the top 10 positions of the ranking, we find Denmark, Netherlands, and Luxembourg, countries with relatively high fertility rates, while among the bottom positions of the ranking, we find Latvia, Cyprus, and Greece, countries with relatively low fertility rates. Thus, countries with relatively high fertility rates are ranked among the top positions, while countries with relatively low fertility rates are ranked among the bottom positions, consistent with the IMFI being positively correlated with fertility rates in European countries $(0.74)$. Thus, the IMFI proves useful in capturing cross-country differences in the conditions for having children, and countries with relatively better levels of such conditions are ranked in the top positions of the index.

Looking at the four dimensions that comprise the IMFI, and their correlational structure with fertility rates, we observe that the Economy and family and Attitudes and habits dimensions are negatively correlated with fertility rates, while the Work-life balance and Policy dimensions are positively correlated with fertility rates. These results suggest that countries with high relative values in the Economy and family and Attitudes and habits dimensions are penalized in the IMFI, while countries with relatively high values of the Work-life balance and Policy dimensions are rewarded with a higher value of the index. Thus, those countries with relatively high values of the Work-life balance and Policy dimensions, and relatively low values of the Economy and family and Attitudes and habits dimensions, are expected to be ranked in the upper levels of the IMFI.

In Figure 1, we observe significant cross-country differences in the dimensions of Economy and family and Attitudes and habits. Denmark, Sweden, the United Kingdom, and Ireland have relatively low values for the Economy and family dimension, while Spain and Greece present relatively high values in this dimension, probably penalized because of their high unemployment rates. Relatively high values for the Work-life balance dimension are shown for Denmark, the Netherlands, Sweden, and Finland, which may indicate that in those countries workers enjoy better job flexibility, and balance in their household responsibilities. In summary, Northern European countries stand out among all countries in the dimensions of Economy and Family and Work-Life balance dimensions, while the United Kingdom and Ireland stand out among countries in the dimensions of Economy and Family and Policy dimensions. We highlight the case of Bulgaria, where having outstanding family policies places the country at a high rank for fertility. Furthermore, to the extent that unemployment rates have a positive contribution to the Economy and family dimension, and given the negative contribution of the Economy and family dimension to the IMFI, efforts should be made to decrease the unemployment rates of young people, and of the population in general. The Work-life balance dimension indicates that fewer hours of work per week and more flexible work conditions could 
lead to higher fertility rates, as they have a negative and positive contribution to the Work-life balance dimension, respectively. Finally, the Policy dimension indicates that more generous family benefits, higher expenditures aimed at increasing the numbers of children under age 3 in formal education, and a longer duration of maternity leave, would clearly contribute to higher fertility rates, and thus governments should also focus on these factors if they aim to increase their fertility rates.

\section{Conclusions}

During the past decade, below-replacement fertility in most developed countries has drawn the attention of researchers in a variety of social science disciplines. Countries such as Spain, Italy, and Poland are the leading examples, with average total fertility rates of 1.3. Below-replacement fertility presents distinct economic challenges for a society, as it changes the age structure of the population and may require structural adaptations. Much of this prior research has analyzed the factors affecting the fertility of women. Here we adopt a global perspective, using a set of variables measured at the country level to evaluate the conditions for having children in Europe.

Using data from twenty-eight European countries, we construct the IMFI, comprising four categories. We find that Denmark, the Netherlands, and Luxembourg are among the countries with the highest values of the index, and they also have high fertility rates within the EU. At the other end of the spectrum, Latvia, Cyprus, and Greece are ranked among the last positions according to our index, countries that also present low values in their fertility rates. We also find a positive correlation between the value of our index and country fertility rates, an indication that our index may be capturing country differences in conditions for childbirth and childrearing.

Our results show that lower youth unemployment rates, fewer hours of work per week, more flexible working conditions, greater numbers of children under age 3 in formal education, and improved payments for maternity leave, clearly contribute to higher fertility in these countries. Our results may be interesting for policy makers, as cross-country differences in the factors and dimensions may prove relevant in identifying weaknesses, and place an emphasis on the positive factors contributing to the fertility phenomena. If these key factors reside in policy or work-life balance dimensions, policies focusing on these factors may be proposed as a way to improve the fertility behavior in these countries. But if differences are identified in attitudes or habits, this may present larger problems, as these values tend to be constant over time, and changing such values can be more of a challenge. Our research may serve as a first step in identifying cross-country differences and the underlying factors affecting the fertility behaviour of individuals. However, we acknowledge that the decision to have children is personal and 
should be taken seriously, with a high degree of responsibility. Thus, our index does not capture all the factors behind fertility patterns, which explains why it is not a perfect measure of fertility. To the extent that more data becomes available, the index can be included in further analysis, which would improve our understanding of the fertility phenomena.

\section{COMPLIANCE WITH ETHICAL STANDARDS}

This research does not involve Human Participants, nor Animals. The authors declare that they have no conflict of interest.

\section{REFERENCES}

Angelini, V., and A. Laferrère (2013). "Parental altruism and nest leaving in Europe: evidence from a retrospective survey," Review of Economics of the Household 11, 393-420.

Angelini, V., A. Laferrère and G. Pasini (2011). "Nest leaving in Europe," in The Individual and the Welfare State, eds. Börsch-Supan, Brandt, Hank and Schröder, pp 67-80. Springer

Baizán, P., B. Arpino and C. Delclòs (2014). "La fecundidad y la difusión de los valores de igualdad de género," Obra Social "la Caixa”, Colección Estudios Sociales nº 36.

Balbo, N., F.C. Billari and M. Mills (2013). "Fertility in advanced societies: A review of research," European Journal of Population 29, 1-38.

Becker, S., S. Bentolila, A. Fernandez and A. Ichino (2010). "Youth Emancipation and Perceived Job Insecurity of Parents and Children," Journal of Population Economics 23, 1047-1071.

Begall, K., and M. Mills (2011). "The impact of subjective work control, job strain and workfamily conflict on fertility intentions: a European comparison," European Journal of Population 27, 433-456.

Bellido, H., J.I. Gimenez-Nadal and R. Ortega (2011). "Measuring Satisfaction of the Unemployed: A Composite Indicator and Policy Implications," Applied Economics Letters $18,1687-1690$.

Bernhardt, E. (1993). “Fertility and employment,” European Sociological Review, 9(1), 25-42.

Billari, F.C. (2005) "Partnership, childbearing and parenting: trends of the 1990s," in M. Macura, A.L. MacDonald and W. Haug (eds.): The new demographic regime: population challenges and policy responses, Geneva: United Nations, 63-94. 
Billari, F.C., and H.P. Kohler (2004). "Patterns of low and very low fertility in Europe," Population Studies 58, 161-176.

Bongaarts, J., and T. Sobotka (2012). "A demographic explanation for the recent rise in European fertility," Population and Development Review, 38(1), 83-120.

Bonoli, G. (2008). "The impact of social policy on fertility: evidence from Switzerland," Journal of European Social Policy 18, 64-77.

Bradshaw, J. And N. Finch (2003). "Overlaps in dimensions of poverty," Journal of Social Policy 32, 513-525.

Brewster, K.L., and R.R. Rindfuss (2000). "Fertility and women's employment in industrialized nations," Annual Review of Sociology 26, 271-296.

Bumpass, L.L. (1990). "What is happening to the family? Interactions between demographic and institutional change," Demography 27, 483-498.

Castro-Martín, T., and T. Martín-García (2014). "Fecundidad bajo mínimos en España: pocos hijos, a edades tardías y por debajo de las aspiraciones reproductivas," Obra Social "la Caixa”, Colección Estudios Sociales no 36.

— and L. Rosero-Bixby (2011). "Maternidades y fronteras. La fecundidad de las mujeres inmigrantes en Espana," Revista Internacional de Sociología, 69(1), 105-137.

De la Rica, S., and A. Iza (2005). "Career planning in Spain: do fixed-term contracts delay marriage and parenthood?" Review of Economics of the Household 3, 49-73.

Drobnic, S., and A.M. Guillén-Rodríguez (2011). "Tensions between work and home: job quality and working conditions in the institutional contexts of Germany and Spain," Social Politics 18, 232-268.

Eagly, A.H., and S. Chaiken (1993). The psychology of attitudes. Orlando, FL, US: Harcourt Brace Jovanovich College Publishers

Esping-Andersen, G. (ed.) (2013). "El déficit de natalidad en Europa. La singularidad del caso español," Obra Social "la Caixa”, Colección Estudios Sociales nº 36.

Esping-Andersen, G., and F.C. Billari (2012). "Re-theorizing family demographics,” Universitat Pompeu Fabra working paper.

Eurobarometer (2011). Eurobarometer on Fertility and Social Climate - evidence on family sizes in Europe, European Commission.

Fernandez-Crehuet, J.M., J.I. Gimenez-Nadal and L. E. Reyes (2016). "The National Work-Life Balance Index(C: The European case," Social Indicators Research, forthcoming. 
Filmer, D., and L. Pritchett (2001). "Estimating wealth effect without expenditure data—or tears: An application to educational enrollments in states of India," Demography 38, 115132.

Galor, O., and D.N. Weil (1996). "The Gender Gap, Fertility, and Growth," American Economic Review 86, 374-387.

Gauthier, A.H. (2007). "The impact of family policies on fertility in industrialized countries: a review of the literature" Population Research and Policy Review 26, 323-346.

Gauthier, A.H., and J. Hatzius (1997). "Family Benefits and Fertility: An Econometric Analysis" Population Studies: A Journal of Demography 51, 295-306.

Goldstein, J.R., T. Sobotka and A. Jasilioniene (2009). "The end of lowestlow fertility?" Population and Development Review 35, 663-700.

González, M.J., and T. Jurado-Guerrero (2006). "Remaining childless in affluent economies: a comparison of France, West Germany, Italy and Spain, 1994-2001,” European Journal of Population 22, 317-352.

Hotelling, H. (1933). "Analysis of a Complex of Statistical Variables Into Principal Components," Journal of Educational Psychology 24, 417-441.

Kiernan, K.E. (2001). "The rise of cohabitation and childbearing outside of marriage in Western Europe," InterInternational Journal of Law, Policy and the Family 15, 1-21.

Kohler, H.P., F.C. Billari and J.A. Ortega J.A. (2002). "The emergence of lowest-low fertility in Europe during the 1990s," Population and Development Review 28, 641-680.

Kolenikov, S. (2009). "Confirmatory factor analysis using confa," The Stata Journal 9, 329373.

Krishnakumar, J., and A.L. Nagar (2008). “On Exact Statistical Properties of Multidimensional Indices Based on Principal Components, Factor Analysis, MIMIC and Structural Equation Models," Social Indicators Research 86, 481-196.

Lai, R. (2003). "Principal Component Analysis on Human Development Indicators of China," Social Indicators Research 61, 319-330.

Lutz, W., and S. Scherbov (2002). "Can immigration compensate for Europe's low fertility?" Interim report, IR-02-052, Vienna Institute of Demography of the Austrian Academy of Sciences, European Demographic Research Papers, 1.

McDonald, P. (2002). "Low fertility: unifying the theory and the demography," paper presented at Population Association of America Meetings, Atlanta, 9-11 May. 
Miller-Torr, B., and S. Short (2004). "Second births and the second shift: a research note on gender equity and fertility," Population and Development Review 30, 109-130.

Mishra, S.K. (2007). "A Comparative Study of Various Inclusive Indices and the Index Constructed by the Principal Components Analysis," MPRA Paper, No. 3377

Momota, M. (2000). “The gender gap, gertility, subsidies and growth,” Economics Letters 69, 401-405.

Myrskylä, M., F.C. Billari and H.P. Kohler (2011). "High development and fertility: fertility at older reproductive ages and gender equality explain the positive link," MPIDR Working Papers WP-2011-017, Max Planck Institute for Demographic Research, Rostock, Germany.

Myrskylä, M., H.P. Kohler and F.C. Billari (2009). “Advances in development reverse fertility declines," Nature 460, 741-743.

Nardo, M., S. Tarantola, A. Saltelli, C. Andropoulos, R. Buescher, G. Karageorgos, A. Latvala and F. Noel (2004). "The e-business readiness composite indicator for 2003: a pilot study," EUR 21294.

Nicoletti G., S. Scarpetta and O. Boylaud (2000). "Summary indicators of product market regulation with an extension to employment protection legislation" OECD, Economics department working papers No. 226, ECO/WKP(99)18.

OECD (2008). Handbook on Constructing Composite Indicators. Methodology and user guide. Paris: OECD Publications.

OECD (2011): Doing better for families, Paris: OECD Publishing.

Olson, J.M., P.A. Vernon, J.A.Harris and K.L. Jang (2001). "The heritability of attitudes: A study of twins," Journal of Personality and Social Psychology 80, 845-860

Örsal, D.D.K., and J.R. Goldstein (2010). "The increasing importance of economic conditions on fertility,” MPIDR Working Papers WP-2010-014, Max Planck Institute for Demographic Research, Rostock, Germany.

Pascall, G., \& Lewis, J. (2004). “Emerging gender regimes and policies for gender equality in a wider Europe," Journal of Social Policy 33, 373-394.

Ram, R. (1982). "Composite Indices of Physical Quality of Life, Basic Needs Fulfilment, and Income. A 'Principal Component' Representation.” Journal of Development Economics 11, 227-247.

Rindfuss, R., K. B. Guzzo, and S. P. Morgan (2003). "The changing institutional context of low fertility," Population Research and Policy Review 22, 411-438. 
Roig Vila, M., and T. Castro-Martín (2007). "Childbearing patterns of foreign women in a new immigration country: the case of Spain," Population-E 62(3), 351-380.

Satorra, A., and P. M. Bentler (1994). Corrections to test statistics and standard errors in covariance structure analysis. In Latent Variables Analysis, ed. A. von Eye and C. C. Clogg, 399-419. Thousand Oaks, CA: Sage

Seltzer, J.A. (2000). "Families formed outside of marriage," Journal of Marriage and the Family 62, 1247-1268.

Spector, P.E. (1992). Summated rating scale construction: An introduction. Newbury Park, CA: Sage.

Tarabusi, E.C., and G. Guarini (2013). "An Unbalance Adjustment Method for Development Indicators," Social Indicators Research 112, 19-45.

Tesser, A. (1993). "The Importance of Heritability in Psychological Research: The Case of Attitudes," Psychological Review 100, 129-142.

Testa, M.R. (2012). "Family sizes in Europe: evidence from the 2011 Eurobarometer Survey," European Demographic Research Papers, 2, Vienna Institute of Demography.

Thévenon, O. (2011). "Family policies in OECD countries: a comparative analysis," Population and Development Review 37, 57-87.

Thévenon, O., and A. Luci (2012). "Reconciling work, family and child outcomes: what implications for family support policies?" Population Research and Policy Review 31, 855882.

Vignoli, D., S. Dresfahl and G. De Santis (2012). "Whose job instability affects the likelihood of becoming a parent in Italy? A tale of two partners," Demographic Research 26, 41-62.

Weil, D. (1999). "Population Growth, Dependency, and Consumption: Why Has Fertility Fallen below Replacement in Industrial Nations, and Will It Last?," American Economic Review 89, $251-255$.

\section{DATA SOURCES}

EUROPEAN VALUES STUDY (2008). European Values Study 2008

EUROFOUND (2010). European Working Conditions Survev 2010

EUROFOUND (2012). European Quality of Life Survey 2012

EUROSTAT (2010, 2012). EUROSTAT Statistics web page 
OECD. OECD Family Database 
Figure 1. Comparison of the four dimensions of the International Multidimensional Fertility Index

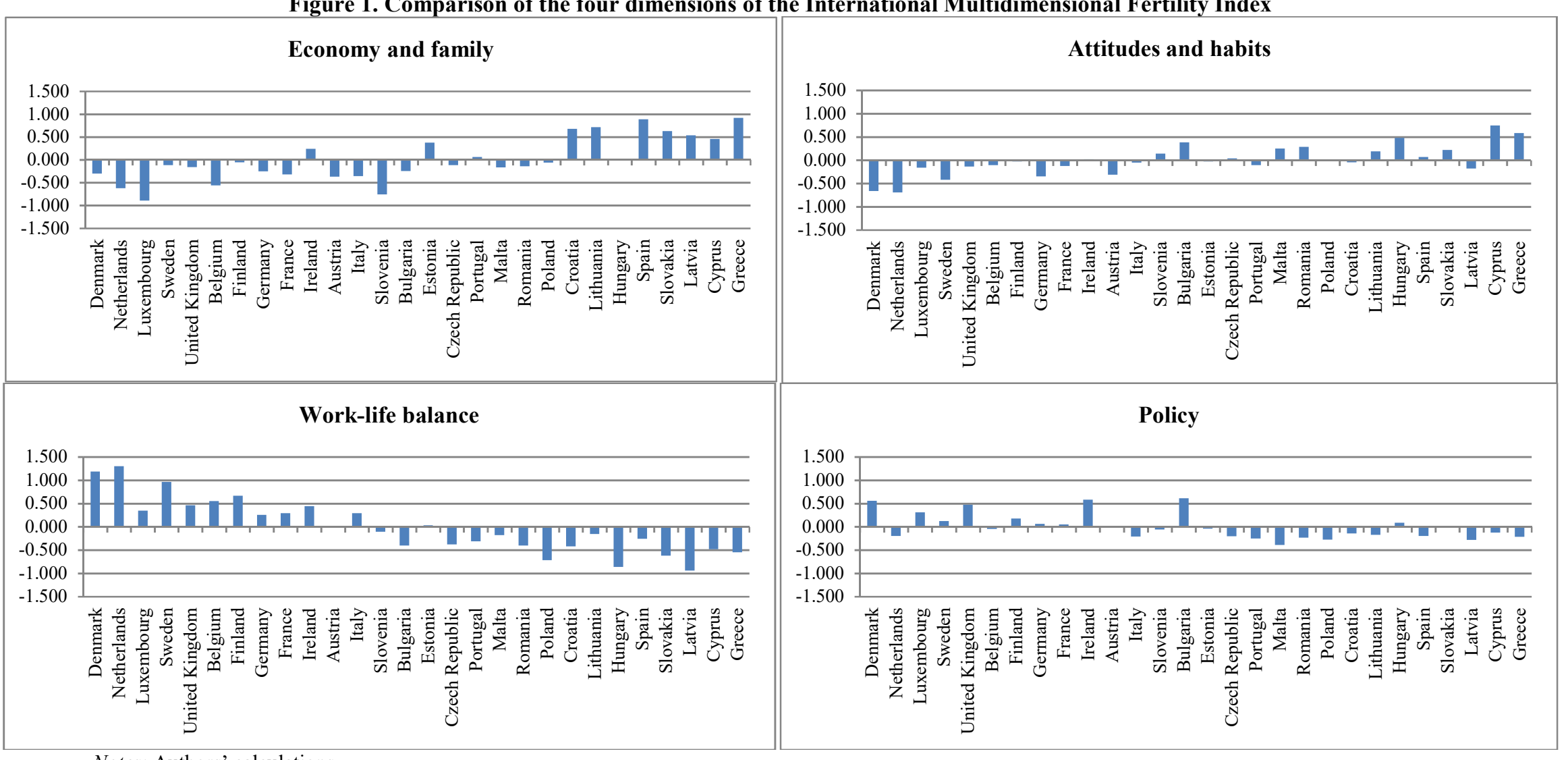


Table 1. Summary Statistics of variables used for the computation of the International Multidimensional Fertility Index

\begin{tabular}{|c|c|c|c|c|c|c|c|c|c|c|c|}
\hline \multirow[b]{2}{*}{ Country } & \multicolumn{5}{|c|}{ Economy and family } & \multicolumn{6}{|c|}{ Attitudes and habits } \\
\hline & $\begin{array}{c}\text { Average } \\
\text { gender } \\
\text { wage gap }\end{array}$ & $\begin{array}{c}\text { Youth } \\
\text { unemp. } \\
\text { rates }\end{array}$ & $\begin{array}{c}\text { Total } \\
\text { unemp. } \\
\text { Rates } \\
\end{array}$ & $\begin{array}{c}\text { \% young } \\
\text { people } \\
\text { living with } \\
\text { parents }\end{array}$ & $\begin{array}{c}\text { Crude } \\
\text { marriage } \\
\text { rates }\end{array}$ & $\begin{array}{c}\text { Ideal number } \\
\text { of children } \\
\text { for females }\end{array}$ & $\begin{array}{c}\text { Family is } \\
\text { important } \\
\text { in life }\end{array}$ & $\begin{array}{c}\text { Importance } \\
\text { of children } \\
\text { for marriage }\end{array}$ & $\begin{array}{c}\text { Women } \\
\text { prefer home } \\
\text { and children }\end{array}$ & $\begin{array}{c}\text { Work } \\
\text { always } \\
\text { comes first }\end{array}$ & $\begin{array}{c}\text { Reaching the } \\
\text { limit of } \\
\text { population }\end{array}$ \\
\hline Austria & 23.70 & 7.27 & 4.30 & 63.30 & 4.47 & 1.59 & 96.23 & 85.57 & 48.99 & 54.35 & 63.01 \\
\hline Belgium & 10.13 & 14.77 & 7.70 & 61.70 & 3.75 & 2.41 & 98.32 & 85.07 & 54.29 & 36.71 & 64.32 \\
\hline Bulgaria & 13.57 & 19.17 & 11.30 & 76.83 & 3.03 & 1.99 & 99.37 & 98.45 & 72.36 & 66.78 & 55.69 \\
\hline Croatia & 17.03 & 28.60 & 14.10 & 86.40 & 4.83 & 2.34 & 98.78 & 92.60 & 54.61 & 40.54 & 53.05 \\
\hline Cyprus & 16.47 & 15.70 & 8.70 & 72.57 & 7.10 & 2.65 & 99.82 & 98.31 & 71.61 & 65.66 & 72.07 \\
\hline Czech Republic & 22.07 & 12.63 & 7.00 & 73.00 & 4.37 & 2.21 & 96.00 & 93.82 & 70.72 & 47.89 & 58.59 \\
\hline Denmark & 15.70 & 12.97 & 7.53 & 36.13 & 5.20 & 2.48 & 98.29 & 72.74 & 11.07 & 48.27 & 56.23 \\
\hline Estonia & 28.33 & 19.23 & 13.00 & 56.67 & 4.13 & 2.12 & 95.22 & 94.24 & 69.02 & 38.64 & 64.47 \\
\hline Finland & 19.77 & 14.90 & 7.97 & 37.47 & 5.40 & 2.51 & 97.93 & 82.56 & 36.23 & 34.34 & 86.30 \\
\hline France & 15.53 & 17.37 & 9.43 & 50.83 & 3.73 & 2.58 & 97.88 & 92.49 & 55.30 & 37.51 & 47.93 \\
\hline Germany & 22.30 & 8.13 & 6.07 & 64.37 & 4.70 & 1.96 & 95.08 & 83.51 & 36.19 & 60.92 & 64.61 \\
\hline Greece & 15.00 & 34.30 & 18.37 & 76.00 & 4.87 & 2.28 & 98.91 & 97.19 & 74.98 & 55.09 & 76.35 \\
\hline Hungary & 18.57 & 18.47 & 11.00 & 79.13 & 3.60 & 1.99 & 98.90 & 96.33 & 65.79 & 61.94 & 75.54 \\
\hline Ireland & 13.33 & 22.93 & 14.43 & 67.65 & 4.45 & 2.47 & 98.80 & 89.92 & 54.91 & 40.41 & 60.53 \\
\hline Italy & 5.93 & 21.97 & 9.17 & 80.13 & 3.53 & 2.12 & 99.64 & 90.84 & 66.82 & 47.60 & 44.79 \\
\hline Latvia & 14.30 & 24.03 & 16.90 & 68.13 & 5.03 & 2.04 & 94.94 & 95.73 & 62.52 & 30.91 & 60.62 \\
\hline Lithuania & 13.03 & 23.33 & 15.53 & 69.80 & 6.40 & 2.20 & 96.60 & 93.71 & 92.50 & 40.51 & 61.54 \\
\hline Luxembourg & 8.67 & 9.63 & 4.83 & 71.43 & 3.40 & 2.10 & 98.57 & 84.52 & 48.13 & 48.36 & 61.71 \\
\hline Malta & 6.50 & 9.90 & 6.53 & 85.20 & 6.40 & 1.90 & 99.25 & 93.83 & 77.81 & 45.60 & 65.13 \\
\hline Netherlands & 17.53 & 7.17 & 4.73 & 53.07 & 4.33 & 2.32 & 95.90 & 79.08 & 38.10 & 25.87 & 54.86 \\
\hline Poland & 5.47 & 17.57 & 9.83 & 75.30 & 5.57 & 2.05 & 99.52 & 94.04 & 67.98 & 38.64 & 50.53 \\
\hline Portugal & 13.67 & 22.67 & 13.57 & 78.17 & 3.50 & 1.71 & 98.91 & 89.98 & 48.83 & 53.39 & 59.14 \\
\hline Romania & 9.83 & 15.47 & 7.00 & 77.20 & 5.43 & 1.92 & 98.43 & 96.64 & 83.25 & 57.80 & 55.73 \\
\hline Slovakia & 20.53 & 23.60 & 14.07 & 87.97 & 4.73 & 1.95 & 98.87 & 97.70 & 56.07 & 59.36 & 60.44 \\
\hline Slovenia & 1.90 & 15.23 & 8.13 & 80.87 & 3.27 & 2.30 & 97.35 & 94.74 & 64.02 & 47.18 & 62.05 \\
\hline Spain & 17.27 & 35.53 & 22.03 & 75.23 & 3.50 & 2.09 & 98.95 & 93.37 & 48.43 & 52.11 & 61.15 \\
\hline Sweden & 15.70 & 17.50 & 8.13 & 41.10 & 5.20 & 2.66 & 94.98 & 83.00 & 30.69 & 35.32 & 66.10 \\
\hline United Kingdom & 19.57 & 15.23 & 7.93 & 56.17 & 4.40 & 2.42 & 98.34 & 81.26 & 45.78 & 35.74 & 73.63 \\
\hline
\end{tabular}

Notes: Sources are EUROSTAT, EUROFOUND, OECD and European Values Study. Average gender wage gap, total unemployment rates, youth unemployment rates, and \% young people living with parents are measured in percentage points. Crude marriage rates are measured in people per 1,000 population. Family is important in life, importance of children for marriage, women prefer home and children, work always comes first, and reaching the limit of population are measured as the percentage of people answering "agree" or "strongly agree", or "very important" or "rather important", to the corresponding statement. 
Table 1. Summary Statistics of variables used for the computation of the International Multidimensional Fertility Index (cont')

\begin{tabular}{|c|c|c|c|c|c|c|c|c|}
\hline \multirow[b]{2}{*}{ Country } & \multicolumn{5}{|c|}{ Work-Life Balance } & \multicolumn{3}{|c|}{ Policy } \\
\hline & $\begin{array}{c}\begin{array}{c}\text { Weekly hours } \\
\text { of work }\end{array} \\
\end{array}$ & $\begin{array}{l}\text { Level of stress } \\
\text { due to work- } \\
\text { life balance } \\
\end{array}$ & $\begin{array}{c}\begin{array}{c}\text { Flexibility to } \\
\text { change work } \\
\text { schedule }\end{array} \\
\end{array}$ & $\begin{array}{c}\text { Flexibility to } \\
\text { accumulate } \\
\text { hours of work }\end{array}$ & $\begin{array}{l}\text { Flexibility to } \\
\text { take a day off }\end{array}$ & $\begin{array}{c}\text { \% of GDP } \\
\text { spent on family } \\
\text { benefits }\end{array}$ & $\begin{array}{c}\% \text { of children } \\
<3 \text { in formal } \\
\text { education }\end{array}$ & $\begin{array}{c}\text { Duration of } \\
\text { maternity leave }\end{array}$ \\
\hline Austria & 37.73 & 11.70 & 39.40 & 56.90 & 46.80 & 2.90 & 12.33 & 16.00 \\
\hline Croatia & 39.73 & 19.00 & 24.00 & 32.60 & 74.90 & 1.63 & 11.67 & 24.00 \\
\hline Cyprus & 39.90 & 22.00 & 32.00 & 25.60 & 71.20 & 1.90 & 24.33 & 18.00 \\
\hline Czech Republic & 41.07 & 20.40 & 30.50 & 53.70 & 70.90 & 1.20 & 3.33 & 28.00 \\
\hline Denmark & 33.63 & 4.80 & 64.70 & 64.70 & 77.20 & 4.13 & 73.00 & 18.00 \\
\hline France & 37.97 & 11.00 & 47.10 & 40.70 & 73.60 & 2.53 & 42.33 & 16.00 \\
\hline Germany & 35.57 & 8.30 & 44.10 & 51.30 & 44.10 & 3.17 & 22.67 & 14.00 \\
\hline Greece & 42.10 & 18.70 & 35.50 & 25.70 & 64.70 & 1.73 & 15.67 & 17.00 \\
\hline Hungary & 39.57 & 22.50 & 18.20 & 38.80 & 44.50 & 2.80 & 8.33 & 24.00 \\
\hline Ireland & 34.97 & 12.60 & 43.70 & 44.50 & 76.20 & 3.43 & 25.00 & 42.00 \\
\hline Italy & 37.47 & 7.50 & 40.60 & 42.10 & 68.50 & 1.37 & 23.00 & 20.00 \\
\hline Netherlands & 30.47 & 4.60 & 55.40 & 58.10 & 84.00 & 1.17 & 49.33 & 16.00 \\
\hline Poland & 40.60 & 25.10 & 32.50 & 54.60 & 44.00 & 1.17 & 3.67 & 24.00 \\
\hline Portugal & 39.03 & 15.50 & 34.20 & 29.90 & 57.80 & 1.27 & 36.33 & 15.00 \\
\hline Romania & 40.30 & 15.30 & 30.20 & 43.40 & 54.80 & 1.50 & 8.00 & 21.00 \\
\hline Slovakia & 40.67 & 18.60 & 29.10 & 44.20 & 46.10 & 1.80 & 4.00 & 34.00 \\
\hline Slovenia & 39.57 & 15.00 & 27.60 & 70.30 & 67.20 & 2.17 & 37.33 & 15.00 \\
\hline Spain & 38.47 & 20.50 & 37.30 & 24.50 & 72.70 & 1.43 & 37.67 & 16.00 \\
\hline Sweden & 36.33 & 6.40 & 62.50 & 71.10 & 76.80 & 3.13 & 51.33 & 10.00 \\
\hline United Kingdom & 36.40 & 14.50 & 55.90 & 45.90 & 74.90 & 1.93 & 32.33 & 52.00 \\
\hline
\end{tabular}

Notes: Sources are EUROSTAT, EUROFOUND, OECD and European Values Study. Weekly hours of hours is measured in hours per week. Level of stress due to work-life balance is measured as the percentage of individuals responding "At work and at home" to the question "Do you have stress due to work-life balance issues". Flexibility to change work schedule is measured as the percentage of people who replied "yes" to the question "I can vary my start and finish times". Flexibility to accumulate hours of work is measured as the percentage of people who replied "yes" to the question "I can accumulate hours for time off". Flexibility to take a day off is measured as the percentage of people who replied "yes" to the question "I can take a day off in the short run if I need it". Duration of maternity leave is measured in weeks. 
Table 2A. Correlations for variables included in Component "Economy and Family"

\begin{tabular}{|c|c|c|c|c|c|}
\hline Economy and family & $\begin{array}{c}\text { Average } \\
\text { gender wage } \\
\text { gap }\end{array}$ & $\begin{array}{c}\text { Youth } \\
\text { unemp. rates }\end{array}$ & $\begin{array}{c}\text { Total unemp. } \\
\text { rates }\end{array}$ & $\begin{array}{c}\text { \% young } \\
\text { people living } \\
\text { with parents }\end{array}$ & $\begin{array}{c}\text { Crude } \\
\text { marriage } \\
\text { rates }\end{array}$ \\
\hline Average gender wage gap & 1.00 & - & - & - & - \\
\hline Youth unemp. rates & -0.03 & 1.00 & - & - & - \\
\hline Total unemp. rates & 0.08 & 0.95 & 1.00 & - & - \\
\hline \% young people living with parents & -0.35 & 0.35 & 0.32 & 1.00 & - \\
\hline Crude marriage rates & 0.02 & -0.09 & -0.06 & -0.10 & 1.00 \\
\hline
\end{tabular}

Notes: Sources are EUROSTAT, EUROFOUND, OECD and European Values Study.

Table 2B. Correlations for variables included in Component "Attitudes and Habits"

\begin{tabular}{|c|c|c|c|c|c|c|}
\hline Attitudes and habits & $\begin{array}{c}\text { Ideal number } \\
\text { of children } \\
\text { for females }\end{array}$ & $\begin{array}{c}\text { Family is } \\
\text { important in } \\
\text { life }\end{array}$ & $\begin{array}{l}\text { Importance } \\
\text { of children } \\
\text { for marriage }\end{array}$ & $\begin{array}{c}\text { Women } \\
\text { prefer home } \\
\text { and children }\end{array}$ & $\begin{array}{c}\text { Work always } \\
\text { comes first } \\
\end{array}$ & $\begin{array}{l}\text { Reaching the } \\
\text { limit of } \\
\text { population } \\
\end{array}$ \\
\hline Ideal number of children for females & 1.00 & - & - & - & - & - \\
\hline Family is important in life & 0.00 & 1.00 & - & - & - & - \\
\hline Importance of children for marriage & -0.28 & 0.29 & 1.00 & - & - & - \\
\hline Women prefer home and children & -0.28 & 0.22 & 0.84 & 1.00 & - & - \\
\hline Work always comes first & -0.42 & 0.40 & 0.43 & 0.24 & 1.00 & - \\
\hline Reaching the limit of population & 0.18 & -0.06 & -0.08 & -0.08 & 0.09 & 1.00 \\
\hline
\end{tabular}


Table 2C. Correlations for variables included in Component "Work-Life Balance"

\begin{tabular}{|c|c|c|c|c|c|}
\hline Work-Life Balance & $\begin{array}{c}\text { Weekly hours } \\
\text { of work }\end{array}$ & $\begin{array}{c}\text { Level of } \\
\text { stress due to } \\
\text { work-life } \\
\text { balance } \\
\end{array}$ & $\begin{array}{c}\text { Flexibility to } \\
\text { change work } \\
\text { schedule } \\
\end{array}$ & $\begin{array}{c}\text { Flexibility to } \\
\text { accumulate } \\
\text { hours of } \\
\text { work } \\
\end{array}$ & $\begin{array}{l}\text { Flexibility to } \\
\text { take a day off }\end{array}$ \\
\hline Weekly hours of work & 1.00 & - & - & - & - \\
\hline Level of stress due to work-life balance & 0.74 & 1.00 & & & \\
\hline Flexibility to change work schedule & -0.74 & -0.77 & 1.00 & - & - \\
\hline Flexibility to accumulate hours of work & -0.44 & -0.49 & 0.49 & 1.00 & - \\
\hline Flexibility to take a day off & -0.34 & -0.39 & 0.41 & 0.19 & 1.00 \\
\hline
\end{tabular}

Table 2D. Correlations for variables included in Component "Policy"

\begin{tabular}{lccc}
\hline \multicolumn{1}{c}{ Table 2D. Correlations for variables included in Component "Policy" } \\
\hline \multicolumn{1}{c}{$\begin{array}{c}\text { \% of GDP } \\
\text { Ppent in } \\
\text { family } \\
\text { benefits }\end{array}$} & $\begin{array}{c}\text { \% of children } \\
<\mathbf{3} \text { in formal } \\
\text { education }\end{array}$ & $\begin{array}{c}\text { Duration of } \\
\text { maternity } \\
\text { leave }\end{array}$ \\
\hline \% of GDP spent on family benefits & 1.00 & - & - \\
\% of children $<3$ in formal education & 0.48 & 1.00 & - \\
Duration of maternity leave & -0.07 & -0.34 & 1.00 \\
\hline Notes: Sources are EUROSTAT, EUROFOUND, OECD and European Values Study.
\end{tabular}

Notes: Sources are EUROSTAT, EUROFOUND, OECD and European Values Study. 
Table 3. Weights applied to each variable

Weights applied to each variable

Economy and family

Average gender wage gap

0.174

Youth unemp. rates

0.196

Total unemp. rates

0.204

$\%$ young people living with parents

0.081

Crude marriage rates

0.215

Attitudes and habits

Ideal number of children for females

0.062

Family is important in life

0.083

Importance of children for marriage

0.141

Women prefer home and children

0.120

Work always comes first

0.084

Reaching the limit of population

\section{Work-life balance}

Weekly hours of work

$-0.166$

Level of stress due to work-life balance

$-0.178$

Flexibility to change work schedule

0.179

Flexibility to accumulate hours of work

0.081

Flexibility to take a day off

0.135

Policy

$\%$ of GDP spent on family benefits

0.180

$\%$ of children $<3$ in formal education

0.079

Duration of maternity leave

0.206

Notes: Authors' calculations. Sources are EUROSTAT, EUROFOUND, OECD and European Values Study. 
Table 4. Ranking of countries according to the International Multidimensional Fertility Index

\begin{tabular}{|c|c|c|c|c|c|c|c|}
\hline Country & $\begin{array}{c}\text { Total } \\
\text { fertility } \\
\text { rate }\end{array}$ & $\begin{array}{c}\text { International } \\
\text { Multidimensional } \\
\text { Fertility Index@ }\end{array}$ & Ranking & $\begin{array}{c}\text { Economy } \\
\text { and family }\end{array}$ & $\begin{array}{c}\text { Attitudes and } \\
\text { habits }\end{array}$ & $\begin{array}{l}\text { Work-life } \\
\text { balance }\end{array}$ & Policy \\
\hline Denmark & 1.73 & 2.701 & 1 & -0.299 & -0.660 & 1.186 & 0.555 \\
\hline Netherlands & 1.72 & 2.418 & 2 & -0.620 & -0.695 & 1.300 & -0.197 \\
\hline Luxembourg & 1.57 & 1.707 & 3 & -0.894 & -0.161 & 0.343 & 0.309 \\
\hline Sweden & 1.91 & 1.618 & 4 & -0.116 & -0.422 & 0.960 & 0.120 \\
\hline United Kingdom & 1.92 & 1.231 & 5 & -0.160 & -0.134 & 0.464 & 0.472 \\
\hline Belgium & 1.79 & 1.177 & 6 & -0.562 & -0.107 & 0.553 & -0.045 \\
\hline Finalnd & 1.80 & 0.928 & 7 & -0.058 & -0.028 & 0.666 & 0.176 \\
\hline Germany & 1.38 & 0.920 & 8 & -0.255 & -0.348 & 0.256 & 0.061 \\
\hline France & 2.01 & 0.792 & 9 & -0.321 & -0.126 & 0.292 & 0.053 \\
\hline Ireland & 2.01 & 0.769 & 10 & 0.240 & 0.020 & 0.444 & 0.585 \\
\hline Austria & 1.44 & 0.677 & 11 & -0.372 & -0.310 & 0.003 & -0.008 \\
\hline Italy & 1.43 & 0.492 & 12 & -0.356 & -0.054 & 0.292 & -0.210 \\
\hline Slovenia & 1.58 & 0.452 & 13 & -0.760 & 0.139 & -0.107 & -0.062 \\
\hline Bulgaria & 1.50 & 0.068 & 14 & -0.244 & 0.384 & -0.405 & 0.613 \\
\hline Estonia & 1.56 & -0.358 & 15 & 0.376 & -0.027 & 0.032 & -0.040 \\
\hline Czech Republic & 1.45 & -0.505 & 16 & -0.114 & 0.036 & -0.380 & -0.203 \\
\hline Portugal & 1.28 & -0.524 & 17 & 0.064 & -0.104 & -0.313 & -0.252 \\
\hline Malta & 1.43 & -0.652 & 18 & -0.164 & 0.251 & -0.178 & -0.388 \\
\hline Romania & 1.53 & -0.783 & 19 & -0.139 & 0.286 & -0.402 & -0.235 \\
\hline Poland & 1.30 & -0.931 & 20 & -0.063 & 0.002 & -0.719 & -0.274 \\
\hline Croatia & 1.51 & -1.195 & 21 & 0.679 & -0.048 & -0.423 & -0.141 \\
\hline Lithuania & 1.60 & -1.234 & 22 & 0.714 & 0.192 & -0.154 & -0.174 \\
\hline Hungary & 1.34 & -1.258 & 23 & 0.000 & 0.478 & -0.863 & 0.084 \\
\hline Spain & 1.32 & -1.410 & 24 & 0.888 & 0.068 & -0.259 & -0.195 \\
\hline Slovakia & 1.34 & -1.447 & 25 & 0.626 & 0.223 & -0.620 & 0.021 \\
\hline Latvia & 1.44 & -1.577 & 26 & 0.534 & -0.180 & -0.940 & -0.284 \\
\hline Cyprus & 1.39 & -1.812 & 27 & 0.459 & 0.744 & -0.483 & -0.127 \\
\hline Greece & 1.34 & -2.265 & 28 & 0.918 & 0.583 & -0.547 & -0.217 \\
\hline
\end{tabular}

Notes: Authors' calculations. Sources are EUROSTAT, EUROFOUND, OECD and European Values Study. 


\section{APPENDIX A: RESULTS FOR THE PRINCIPAL COMPONENTS ANALYSIS (PCA)}

Table A1. Eigenvalues for variables included in Dimension "Economy and Family"

\begin{tabular}{lccc} 
Economy and Family & Eigenvalues & $\begin{array}{c}\text { Variation } \\
\text { Explained }\end{array}$ & $\begin{array}{c}\text { Cummulative } \\
\text { variation } \\
\text { explained }\end{array}$ \\
\hline Component 1 & 2.169 & 0.434 & 0.434 \\
Component 2 & 1.258 & 0.252 & 0.685 \\
Component 3 & 0.982 & 0.197 & 0.882 \\
Component 4 & 0.544 & 0.109 & 0.991 \\
Component 5 & 0.047 & 0.009 & 1.000
\end{tabular}

Notes: Authors' calculations. Sources are EUROSTAT, EUROFOUND, OECD and European Values Study.

Table A2. Rotated factor loadings for variables included in Dimension "Economy and Family"

\begin{tabular}{lccc}
\hline & \multicolumn{3}{c}{ Factor Loadings (Varimax rotation) } \\
\cline { 2 - 4 } Economy and Family & Component 1 & Component 2 & Component 3 \\
\hline Average gender wage gap & -0.097 & $\mathbf{0 . 7 8 0}$ & -0.149 \\
Total unemp. Rates & $\mathbf{0 . 6 3 1}$ & 0.277 & 0.071 \\
Youth unemp. Rates & $\mathbf{0 . 6 4 4}$ & 0.191 & 0.050 \\
\% young people living with parents & $\mathbf{0 . 4 0 5}$ & -0.514 & 0.060 \\
Crude marriage rates & -0.117 & 0.120 & $\mathbf{0 . 9 8 3}$ \\
& & & \\
Variation Explained & 0.434 & 0.252 & 0.197 \\
Variation Explained/Total & 0.492 & 0.285 & 0.223 \\
\hline & Squared factor loadings (scaled to sum unity) \\
\cline { 2 - 4 } Economy and Family & Component 1 & Component 2 & Component 3 \\
\hline Average gender wage gap & 0.009 & $\mathbf{0 . 6 0 9}$ & 0.022 \\
Total unemp. Rates & $\mathbf{0 . 3 9 8}$ & 0.077 & 0.005 \\
Youth unemp. Rates & $\mathbf{0 . 4 1 5}$ & 0.036 & 0.002 \\
\% young people living with parents & $\mathbf{0 . 1 6 4}$ & 0.264 & 0.004 \\
Crude marriage rates & 0.014 & 0.014 & $\mathbf{0 . 9 6 7}$ \\
& & & \\
\hline Notes: Authors' calculations. Sources are EUROSTAT, EUROFOUND, OECD and European Values Study.
\end{tabular}


Table A3. Eigenvalues for variables included in Dimension "Attitudes and Habits"

\begin{tabular}{lccc} 
Attitudes and habits & Eigenvalues & $\begin{array}{c}\text { Variation } \\
\text { Explained }\end{array}$ & $\begin{array}{c}\text { Cummulative } \\
\text { variation } \\
\text { explained }\end{array}$ \\
\hline Component 1 & 2.451 & 0.409 & 0.409 \\
Component 2 & 1.112 & 0.185 & 0.594 \\
Component 3 & 0.986 & 0.164 & 0.758 \\
Component 4 & 0.936 & 0.156 & 0.914 \\
Component 5 & 0.386 & 0.064 & 0.979 \\
Component 6 & 0.129 & 0.021 & 1.000 \\
\hline
\end{tabular}

Notes: Authors' calculations. Sources are EUROSTAT, EUROFOUND, OECD and European Values Study.

Table A4. Rotated factor loadings for variables included in Dimension "Attitudes and Habits"

\begin{tabular}{lcccc}
\hline & \multicolumn{4}{c}{ Factor Loadings (Varimax rotation) } \\
\cline { 2 - 5 } Attitudes and habits & Component $\mathbf{1}$ & Component $\mathbf{2}$ & Component $\mathbf{3}$ & Component 4 \\
\hline Ideal number of children for females & -0.346 & 0.354 & $\mathbf{0 . 5 8 8}$ & 0.359 \\
Family is important in life & 0.315 & 0.434 & -0.088 & $\mathbf{0 . 6 9 9}$ \\
Importance of children for marriage & $\mathbf{0 . 5 6 3}$ & -0.044 & 0.369 & -0.096 \\
Women prefer home and children & $\mathbf{0 . 5 1 9}$ & -0.142 & 0.489 & -0.139 \\
Work always comes first & $\mathbf{0 . 4 3 4}$ & 0.341 & -0.507 & -0.047 \\
Reaching the limit of population & -0.086 & $\mathbf{0 . 7 4 0}$ & 0.119 & -0.593 \\
& & & & 0.156 \\
Variation Explained & 0.409 & 0.185 & 0.164 & 0.171 \\
Variation Explained/Total & 0.447 & 0.203 & 0.180 & \\
\hline & \multicolumn{2}{c}{ Squared factor loadings (scaled to sum unity) } \\
\cline { 2 - 5 } Attitudes and habits & $\mathbf{C o m p o n e n t ~} \mathbf{1}$ & $\mathbf{C o m p o n e n t} \mathbf{2}$ & $\mathbf{C o m p o n e n t ~ 3}$ & $\mathbf{C o m p o n e n t ~ 4}$ \\
\hline Ideal number of children for females & 0.120 & $\mathbf{0 . 1 2 5}$ & 0.346 & 0.129 \\
Family is important in life & 0.099 & $\mathbf{0 . 1 8 9}$ & 0.008 & 0.489 \\
Importance of children for marriage & $\mathbf{0 . 3 1 6}$ & 0.002 & 0.136 & 0.009 \\
Women prefer home and children & $\mathbf{0 . 2 6 9}$ & 0.020 & 0.239 & 0.019 \\
Work always comes first & 0.189 & 0.116 & $\mathbf{0 . 2 5 7}$ & 0.002 \\
Reaching the limit of population & 0.007 & 0.548 & 0.014 & $\mathbf{0 . 3 5 2}$ \\
& & & & \\
\hline
\end{tabular}

Notes: Authors' calculations. Sources are EUROSTAT, EUROFOUND, OECD and European Values Study. 
Table A5. Eigenvalues for variables included in Dimension "Work-Life Balance"

\begin{tabular}{lccc} 
Work-Life Balance & Eigenvalues & $\begin{array}{c}\text { Variation } \\
\text { Explained }\end{array}$ & $\begin{array}{c}\text { Cummulative } \\
\text { variation } \\
\text { explained }\end{array}$ \\
\hline Component 1 & 3.084 & 0.617 & 0.617 \\
Component 2 & 0.823 & 0.165 & 0.781 \\
Component 3 & 0.606 & 0.121 & 0.903 \\
Component 4 & 0.258 & 0.052 & 0.954 \\
Component 5 & 0.229 & 0.046 & 1.000
\end{tabular}

Notes: Authors' calculations. Sources are EUROSTAT, EUROFOUND, OECD and European Values Study.

Table A6. Rotated factor loadings for variables included in Dimension "Work-Life Balance"

\begin{tabular}{lccc}
\hline & \multicolumn{2}{c}{ Factor Loadings (Varimax rotation) } \\
\hline Work-Life Balance & Component 1 & Component 2 & Component 3 \\
\hline Weekly hours of work & $\mathbf{- 0 . 4 9 3}$ & 0.079 & 0.388 \\
Level of stress due to work-life balance & $\mathbf{- 0 . 5 1 1}$ & 0.050 & 0.222 \\
Flexibility to change work schedule & $\mathbf{0 . 5 1 2}$ & -0.029 & -0.208 \\
Flexibility to accumulate hours of work & 0.372 & -0.502 & $\mathbf{0 . 7 7 5}$ \\
Flexibility to take a day off & 0.309 & $\mathbf{0 . 8 6 0}$ & 0.397 \\
& & & \\
Variation Explained & 0.617 & 0.165 & 0.121 \\
Variation Explained/Total & 0.683 & 0.182 & 0.134 \\
\hline & Squared factor loadings (scaled to sum unity) \\
\hline Work-Life Balance & & & \\
& Component 1 & Component 2 & Component 3 \\
\hline Weekly hours of work & $\mathbf{0 . 2 4 3}$ & 0.006 & 0.150 \\
Level of stress due to work-life balance & $\mathbf{0 . 2 6 1}$ & 0.003 & 0.049 \\
Flexibility to change work schedule & $\mathbf{0 . 2 6 3}$ & 0.001 & 0.043 \\
Flexibility to accumulate hours of work & 0.138 & $\mathbf{0 . 2 5 2}$ & 0.600 \\
Flexibility to take a day off & 0.095 & 0.739 & $\mathbf{0 . 1 5 7}$ \\
& & & \\
\hline Notes: Authors' calculations. Sources are EUROSTAT, EUROFOUND, OECD and European Values Study.
\end{tabular}


Table A7. Eigenvalues for variables included in Dimension "Policy"

\begin{tabular}{lccc}
\hline Policy & Eigenvalues & $\begin{array}{c}\text { Variation } \\
\text { Explained }\end{array}$ & $\begin{array}{c}\text { Cummulative } \\
\text { variation } \\
\text { explained }\end{array}$ \\
\hline Component 1 & 1.620 & 0.540 & 0.540 \\
Component 2 & 0.933 & 0.311 & 0.851 \\
Component 3 & 0.447 & 0.149 & 1.000
\end{tabular}

Notes: Authors' calculations. Sources are EUROSTAT, EUROFOUND, OECD and European Values Study.

Table A8. Rotated factor loadings for variables included in Dimension "Policy"

\begin{tabular}{|c|c|c|c|}
\hline \multirow[b]{2}{*}{ Policy } & \multicolumn{3}{|c|}{ Factor Loadings (Varimax rotation) } \\
\hline & Component 1 & Component 2 & Component 3 \\
\hline$\%$ of GDP spent on family benefits & 0.58 & 0.58 & 0.33 \\
\hline$\%$ of children $<3$ in formal education & 0.69 & 0.04 & 0.73 \\
\hline Duration of maternity leave & -0.44 & 0.81 & 0.37 \\
\hline Variation Explained & 0.54 & 0.31 & 0.15 \\
\hline \multirow[t]{3}{*}{ Variation Explained/Total } & 0.54 & 0.31 & 0.15 \\
\hline & \multicolumn{3}{|c|}{ Squared factor loadings (scaled to sum unity) } \\
\hline & Component 1 & Component 2 & Component 3 \\
\hline$\%$ of GDP spent in family benefits & 0.33 & 0.34 & 0.14 \\
\hline$\%$ of children $<3$ in formal education & 0.47 & 0.00 & 0.68 \\
\hline Duration of maternity leave & 0.19 & 0.66 & 0.18 \\
\hline
\end{tabular}

